\title{
Optimizing Electricity Load and Cost for Demand Side Management in Smart Grid
}

\author{
AYESHA AFZAAL*, AND MOHSIN NAZIR* \\ RECEIVED ON 15.11.2017 ACCEPTED ON 12.02.2018
}

\begin{abstract}
This paper proposes a mechanism for OELC (Optimizing Electricity Load and Cost) for smart grid. The load of every smart home is predicted one-hour prior to their actual usage. To fulfill PL (Predicted Load) of each consumer, multiple resources of electricity are considered, including RE (Renewable Energy) resources. Furthermore, cost to get PL from multiple resources is calculated. In proposed model 3-4 smart homes are grouped in the form of clusters. To reduce the amount of electricity bills, system also allows privileges to share electricity between adjacent smart homes within a cluster. To validate the OELC mechanism, extensive numerical simulations are conducted which shows a significant reduction in electricity load and cost for electricity consumers. In future, to enhance the functionality of OELC, security from cyber-attacks can be considered.
\end{abstract}

Key Words: Smart Grid, Demand Side Management, Real Time Pricing, Peak-to-Average Ratio, Distributed Generation.

\section{INTRODUCTION}

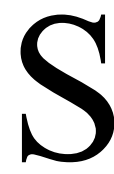

mart grid uses digital technology for transfer of electricity between consumers and suppliers. Electricity provider companies examine consumer's usage pattern and also implement dynamic pricing that varies according to demand of consumers [1-3]. Moreover, consumers can also assess their electricity utilization pattern in a real time environment. In this way, they can reduce their electricity bills by cutting down electricity consumption during peak hours [4-6]. With all the benefits of smart grid, huge increases in electricity bills were also observed by advent of smart appliances. In last five years, average price of electricity for residential consumers is increased to $29 \%$, which is almost $10 \%$ of overall household income [1]. Studies recommend that demand and the price of electricity will continue to increase in future [6].

The easiest way for consumers to cut their electricity bills is to simply reduce their electricity consumption during peak hours, when electricity rates are high [7]. Unfortunately, this dynamic pricing places a burden on electricity consumers to constantly monitor price signals, and then alters the pattern of their electricity consumption to reduce costs without disturbing their daily life [8-9]. This approach is challenging, since electricity consumers are unaware of power consumption of individual devices

Authors E-Mail: (ayesha.afzaal@1cwu.edu.pk, mohsinsage@gmail.com)

* Lahore College for Women University, Lahore, Pakistan. 
and resist thinking about it [10]. Thus, electricity consumers may not respond appropriately to price changes, and they cannot gain the cost-saving benefits of off-peak hours [11].

Over past few years, significant research was conducted on demand side management, which focuses on reducing costs of electricity to end consumers. In particular Hemant proposed an algorithm based on rebound peak condition. A threshold is defined for grid station. Servers are continuously monitored grid as its capacity reaches allowable limit, it stops remaining electrical appliances [12]. The power will be provided to remaining appliances in the next time slot of off-peak hours. In this way grid remains stable and the cost of electricity for end consumer is reduced [3]. Spiliotis et. al. [13] proposed an AP(Action Plan) to reduce cost of electricity. The AP consists of two phases. In first phase load shifting technique for reducing PAR (Peak to Average Rratio) and utilizing cheaper charging hours is implemented and in second phase multiple scenarios are considered for covering thermal and electrical demand of electricity and the one with less expensive is selected. Similarly, Hafeez et. al. [14] proposed a technique for integration of renewable resources for demand side management. A heuristic technique was implemented for scheduling electric appliances to increase revenue, decrease electricity bills and reduce carbon emission [15-16]. To manage electricity load Wang et. al. [17] proposed a PWOA (Particle Swam Optimization Algorithm) using multi-agent technique. The objective of PWOA was to maintain optimal comfort level of users while minimizing power consumption during peak hours. To implement PWOA, electricity consumers give authority to utility companies to shift their load in order to balance energy used. Implementing ICT (Information and Communication Technology) features, smart grid is also recognized as IoT (Internet of Things) [17]. To monitor electricity distribution in the smart grid environment an online algorithm using IoT features is proposed. The problem is shown as convex and solved by decomposing in a distributed manner. The system requires present information of both; the electric grid and their consumers. Amount of electricity consumed and their consumption pattern should be known to the system. Results show that online distributed solution reduced PAR (PreAssessment Result) for hot days [18-19].

Literature shows that lots of methods have already been proposed to reduce cost of electricity and peak to average ratio but the existing methods require user personal information, authority to shift users load or disturb their comfort level [20-23]. Moreover, most of the other cost reduction techniques for smart grid focuses on appliance scheduling, which will ultimately affect the comfort level of electricity consumers [24-25]. There is a need of a mechanism, which will reduce cost of electricity bills for consumers while maintaining their conform level along, keeping users personal information and authorities secure [26-28].

In this paper OELC is proposed. OELC will encourage electricity consumers to switch between small-sized RE resources and electricity supplier companies, to satisfy their demand. In OELC, every smart home is equipped with RE resources behaves like mini micro-grid. Smart home users can get electricity not only from their own mini micro-grid but also from the neighboring smart homes mini micro-grids.

In this way each smart home user is buyer as well as seller of electricity. The system will attempt to fulfill upcoming demand of electricity for each smart home from their own $\mathrm{RE}$ resources. If demand is not completely satisfied, system will consider interested neighboring smart homes for trading of electricity (sell extra units of electricity). At the end, electricity supplier companies will be considered for the remaining demand. In this way, all the demand is

Mehran University Research Journal of Engineering \& Technology, Volume 37, No. 4, October, 2018 [p-ISSN: 0254-7821, e-ISSN: 2413-7219] 
not transferred to the traditional power grid. The overall goal of this research is to reduce load and cost of electricity for end consumers. Moreover, implementing security features in smart grid is out of the scope of this paper as already a lot of work is done in this domain. In future, smart meter and electricity consumption profile of each user can be secured using ARMET [29] technology.

The rest of the paper is organized as follows. Section II gives details of OELC mechanism as well as some infrastructure changes required to implement OELC. The functioning of OELC is analyzed under various settings using a case study in section III. Finally, the conclusion and future recommendations are drawn in section IV.

\section{MATERIALS AND METHOD}

In this paper a novel mechanism for OELC is proposed which will not only overcome the load on the grid by considering multiple resources of electricity, but also reduce the amount of electricity bills for end consumers by performing electricity trading between adjacent smart homes.

\subsection{Infrastructure Requirement for Proposed System}

A small infrastructure changes are required to implement proposed system. It is assumed that 3-4 smart homes are logically gathered called clusters as shown in Fig. 1. Every smart home is equipped with AMI (Advanced Metering Infrastructure) and distributed RE resources forming mini micro-grid. Mini micro-grid of each smart home may consist of solar power plants, wind turbines and battery storage system. Electricity trading is performed between multiple smart homes within a cluster.

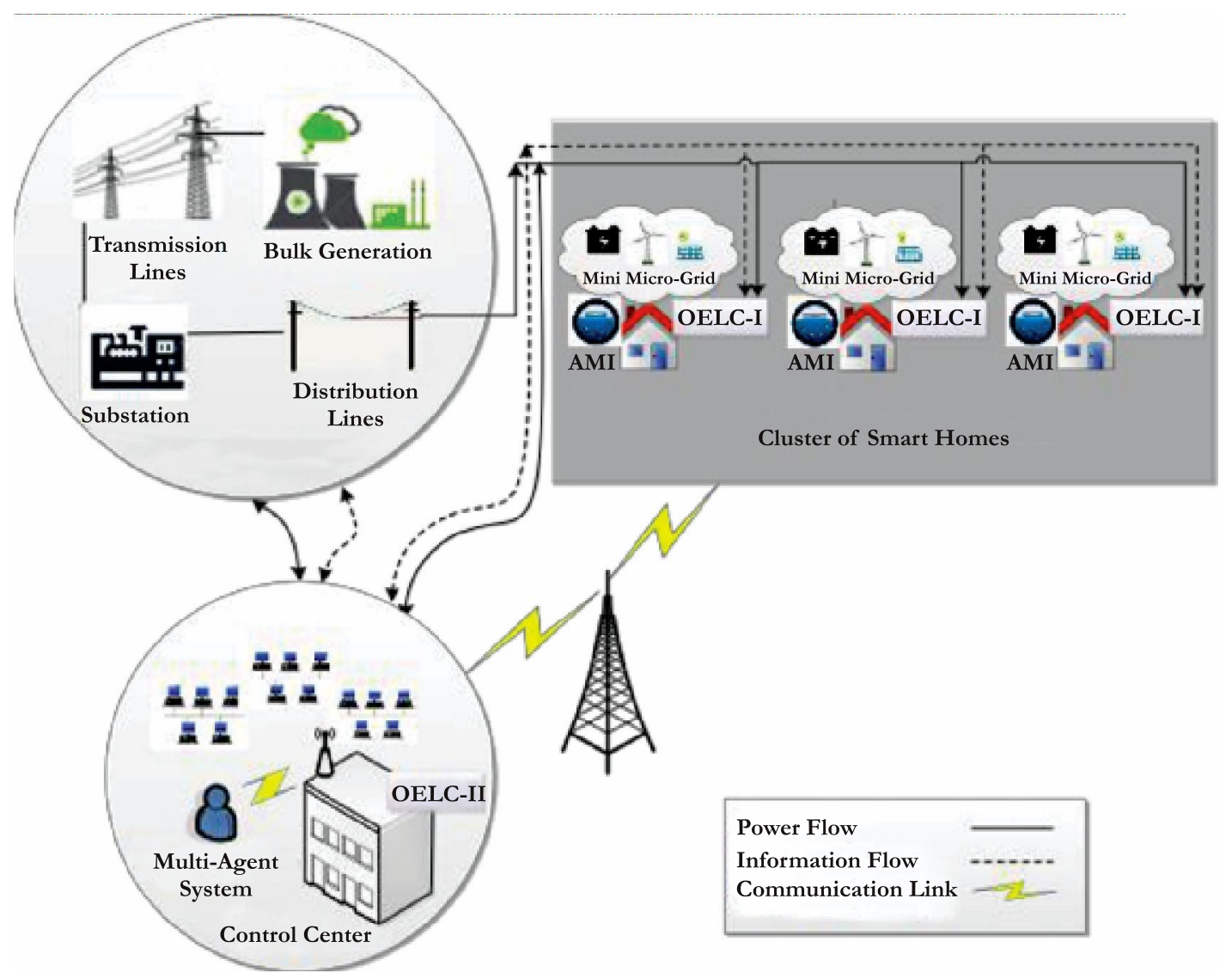

FIG. 1. PROPOSED SYSTEM MODEL FOR OELC WITH MULTI-AGENT SYSTEM AT BOTH PRODUCTION AND CONSUMPTION LEVEL

Mehran University Research Journal of Engineering \& Technology, Volume 37, No. 4, October, 2018 [p-ISSN: 0254-7821, e-ISSN: 2413-7219] 
The proposed system controls the electricity trading at two levels; distributed and centralized. At distributed level OELC-I is deployed at AMI of every smart home, whereas a centralized control is performed at control centers using OELC-II. OELC-I is also monitored and controlled by OELC-II. OELC is programmed using multiagent system. OELC-I calculate predicted load of each smart home as shown in system model Fig. 1 using Algorithm 1 and it is also responsible for the flow of information and energy between adjacent neighboring smart homes within a cluster.

Moreover, to fulfill high demand smart home is also connected with the electric grid. OELC-II is deployed at control centers; it is programmed to control individual OELC-I as well as perform the information and electricity management between the electric grid and smart homes. OELC-I sent the PL ${ }_{i}^{t}$ of each user i for time slot $t$ to OELCII, which will calculate the cost to satisfy PL from multiple resources of electricity. It is considered that there are three main resources of electricity for every smart home user.

- $\quad$ In-house mini Micro-Grid

- $\quad$ Neighboring smart homes' mini micro-grid

- $\quad$ Electric grid

\subsection{Details of OELC}

OELC is explained in six steps given below:

Step-1: The upcoming electricity demand of consumers is calculated by using our previously proposed agentbased weighted average prediction algorithm [30]. System consists of two types of agents; the forecaster agent and a group of expert agents having some associated weights. Weights are assigned to expert agents according to the accuracy of their prediction. Higher weights indicate that expert agent has a more accurate prediction history. The whole day is divided into 24 hours time slots. Electricity load prediction performs one-hour prior to the actual time interval. To calculate the predicted load for time slot $t$, forecaster agent calculates $\mathrm{PL}_{\mathrm{i}}^{\mathrm{t}}$; the upcoming predicted electricity load of customer i for time ( $\mathrm{t}$ ). This calculation is performed at (t-1) hour. $\mathrm{PL}_{\mathrm{i}}^{\mathrm{t}}$ is calculated based on expert agents' advice using Equation (1).

$P L_{1}=\left(\left(f_{1, t} * w_{(1, t-1)} f_{2, t} * w_{(2, t-1)}+f_{3, t} * w_{(3, t-1)}+\ldots+f_{n, t} * w_{(n, t-1)}\right) / N\right)$

Where $f_{j, t}$ is the advice of $j^{\text {th }}$ expert agent, belongs to the set of expert agents' advices $\left(\mathrm{f}_{1, \mathrm{t}} ; \ldots, \mathrm{f}_{\mathrm{n}, \mathrm{t}}\right)$ and $\mathrm{n}$ is total number of expert agents and $\mathrm{w}_{(\mathrm{j}, \mathrm{t}-1)}$ is the weight assigned to $\mathrm{j}^{\text {th }}$ expert agent in the previous time slot. Weights of expert agents are revised after every time slot depending on the accuracy of their prediction. Moreover, when time slot $t$ occurs; actual load $\mathrm{L}_{\mathrm{i}}^{\mathrm{t}}$ of electricity consumer i for time slot $t$ is compared with predicted loads $\mathrm{PL}_{\mathrm{i}}^{\mathrm{t}}$. The objective is to minimize the difference between these two load profiles. To re-assign the weights of expert agents, actual load $\mathrm{L}_{\mathrm{i}}^{\mathrm{t}}$ is also compared with each expert agent' advise. Expert agents' weights are increased whose advice was closer to actual load. Agents weight reassignment is also explained in Algorithm-1.

Step-2: OELC-I will compute cost to fulfill from in-house mini micro-grid. It is calculated using Equation(2):

$\mathrm{C}_{\mathrm{hmg}}=\mathrm{P}_{\mathrm{hmg}}+\mathrm{H}_{\mathrm{hbm}}$

Where $\mathrm{C}_{\mathrm{hmg}}$ is the cost to get PL from in-house mini microgrid, $\mathrm{P}_{\mathrm{hmg}}$ is price for bidding and $\mathrm{H}_{\mathrm{hbm}}$ is hourly payback amount of investment. $\mathrm{P}_{\mathrm{hmg}}$ is the sum of multiple factors as shown in Equation (3).

Mehran University Research Journal of Engineering \& Technology, Volume 37, No. 4, October, 2018 [p-ISSN: 0254-7821, e-ISSN: 2413-7219] 


$$
\mathrm{P}_{\mathrm{hmg}}=\sum_{\mathrm{k}=1}^{\mathrm{n}} \mathrm{C}_{\mathrm{k}} \mathrm{x}+\sum_{\mathrm{j}=\mathrm{p}}^{\mathrm{of}} \mathrm{M}_{\mathrm{j}} \mathrm{x}+\mathrm{S}_{\mathrm{c}}
$$

Where, $\mathrm{C}_{\mathrm{k}}$ is the production cost of electricity and $\mathrm{k}$ is the number of distributed RE resources in each smart home and $x$ is the available units of electricity in RE. $M_{j}$ is price of energy if stored units of RE are received from gird and $\mathrm{j}$ is rate at peak and off-peak hour. $\mathrm{S}_{\mathrm{c}}$ is per unit storage cost of electricity.

Step-3: Smart homes are gathered to make clusters. Every smart home has an adjacent neighbor. The cost to get electricity from adjacent neighbors is stored in the form of the matrix given below.

In matrix rows and columns indicates the neighboring smart homes and index values represent their respective cost, for example $c_{\mathrm{s} 12}$ represent per unit cost for smart home-1 to buy electricity from neighboring smart home2. Similarly a matrix for each smart home is maintained against their neighbors. The value of matrix is updated on hourly basis. Cost to get electricity from neighboring smart home, which is stored in the matrix, is calculated based on Equation (4).

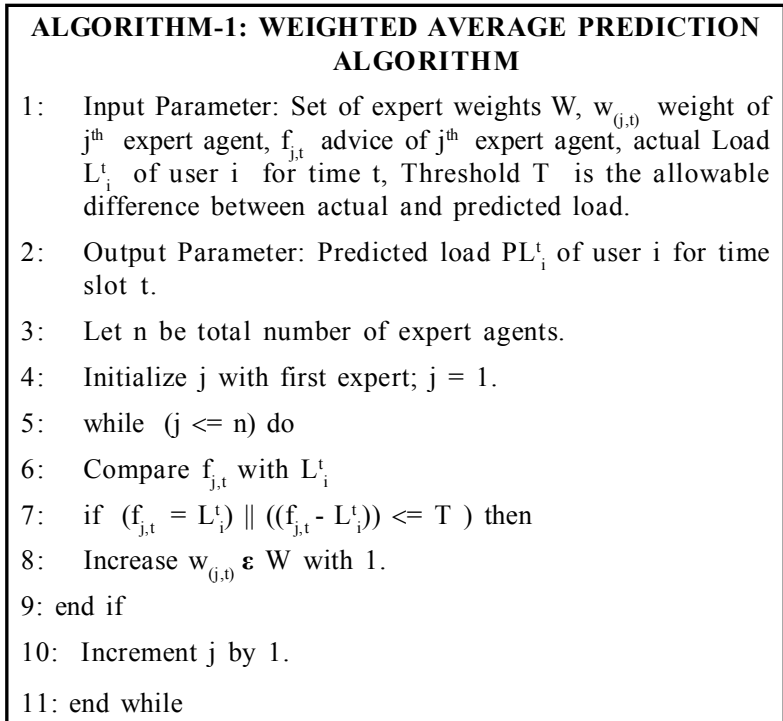

1: Input Parameter: Set of expert weights $\mathrm{W}, \mathrm{w}_{\mathrm{(j,t)}}$ weight of $j^{\text {th }}$ expert agent, $f_{j, t}$ advice of $j^{\text {th }}$ expert agent, actual Load $\mathrm{L}_{\mathrm{i}}^{\mathrm{t}}$ of user $\mathrm{i}$ for time $\mathrm{t}$, Threshold $\mathrm{T}$ is the allowable difference between actual and predicted load.

2: Output Parameter: Predicted load $\mathrm{PL}_{\mathrm{i}}^{\mathrm{t}}$ of user i for time slot $\mathrm{t}$.

3: Let $\mathrm{n}$ be total number of expert agents.

4: Initialize $\mathrm{j}$ with first expert; $\mathrm{j}=1$.

5: while $(\mathrm{j}<=\mathrm{n})$ do

6: Compare $\mathrm{f}_{\mathrm{j}, \mathrm{t}}$ with $\mathrm{L}_{\mathrm{i}}^{\mathrm{t}}$

7: if $\left.\left(\mathrm{f}_{\mathrm{j}, \mathrm{t}}=\mathrm{L}_{\mathrm{i}}^{\mathrm{t}}\right) \|\left(\left(\mathrm{f}_{\mathrm{j}, \mathrm{t}}-\mathrm{L}_{\mathrm{i}}^{\mathrm{t}}\right)\right)<=\mathrm{T}\right)$ then

8: $\quad$ Increase $\mathrm{w}_{(\mathrm{j}, \mathrm{t})} \in \mathrm{W}$ with 1 .

9: end if

10: Increment $\mathrm{j}$ by 1 .

11: end while

$C_{n m g}=P q_{n m g} I_{s_{m}, b}^{\text {loss }}+q_{g} p_{g}+q_{d} p_{d}(1+s)$

Where

$s=s_{a+}^{i}-s_{a-}^{i}$

$\mathrm{C}_{\mathrm{nmg}}$ is the cost to get $\mathrm{PL}$ from neighboring micro-grid. $\mathrm{P}$ is pricing factor, $\mathrm{q}_{\mathrm{nmg}}$ represents the quantity of electricity transferred from neighboring micro-grid, $1^{\text {loss }}$ is the energy losses during transformation of electricity from seller micro-grid $\left(\mathrm{s}_{\mathrm{m}}\right)$ to buyer micro-grid $\left(\mathrm{b}_{\mathrm{m}}\right) \cdot \mathrm{q}_{\mathrm{g}}$ is quantity of electricity that neighboring micro-grid get from grid and $\mathrm{p}_{\mathrm{g}}$ is per unit cost to get electricity from grid. $\mathrm{q}_{d}$ is the quantity of electricity discharged and $\mathrm{p}_{\mathrm{d}}$ is discharging price. 1 represents the load profile and $\mathrm{s}$ is storage profile. Similarly, $\mathrm{s}_{\mathrm{a}^{+}}$is charging profile and $\mathrm{s}_{\mathrm{a}-}$ is discharging profile.

$C=\left[\begin{array}{ccccc}C_{s_{11}} & C_{s_{12}} & C_{s_{13}} & \cdots & C_{s_{1} m} \\ C_{s_{21}} & C_{s_{22}} & C_{s_{23}} & \cdots & C_{s_{2} m} \\ C_{s_{31}} & C_{s_{32}} & C_{s_{33}} & \cdots & C_{s_{3} m} \\ \vdots & \vdots & \vdots & \vdots & \vdots \\ C_{s n_{1}} & C_{s n_{2}} & C_{s n_{3}} & \cdots & C_{s n m}\end{array}\right]$

Step-4: A centralized control OELC -II will control all the OELC-I in each smart home. If PL is not fully satisfied, OELC-I sent request to OELC-II to fulfill remaining electricity demand from the electric grid. OELC-II will calculate the cost to get the remaining PL from the grid using Equation(6).

$\mathrm{C}_{\mathrm{g}}=\mathrm{r}_{\mathrm{t}} * \mathrm{u}_{\mathrm{t}}$

Where $\mathrm{C}_{\mathrm{g}}$ is the cost to fulfill remaining $\mathrm{PL}\left(\mathrm{r}_{\mathrm{t}}\right)$ from the electric grid and $u_{t}$ is per unit cost according to time slot t.

Step-5: OELC-II will compare all three costs calculated above. It will select the cheapest one to fulfill the PL but 
if PL is not fully satisfied from one resource then move towards the second cheapest resource similarly multiple resources of electricity will be selected starting from cheapest to highest until the demand is not completely satisfied.

Step-6: At the end the electricity bill of each user is calculated. This electricity bill is based on the sum of their units consumed from each resource. It is calculated using Algorithm-2.

\section{ALGORITHM-2: UTILITY BILL CALCULATI ON FOR SINGLE USER i}

1: Parameters: $\mathrm{C}_{\mathrm{hm}}$ is per unit cost to get electricity form home micro-grid, $\mathrm{UC}_{\mathrm{hmg}}$ is the units available in-house micro-grid, $\mathrm{C}_{\mathrm{nmg}}$ is per unit cost to get electricity from neighboring micro-grid, $\mathrm{UC}_{\mathrm{nmg}}$ is the units available neighboring smart homes, $\mathrm{C}_{\mathrm{g}}$ is the per unit cost to get electricity from grid, $\mathrm{TC}_{1}, \mathrm{TC}_{2}, \mathrm{TC}_{3}$ is the cost to get electricity from resource 1,2 and 3 respectively. Time slot $\mathrm{t}$, user $\mathrm{i}$.

2: Calculate Predicted Load $\left(\mathrm{PL}_{\mathrm{i}}^{\mathrm{t}}\right)$ of user i for time slot $\mathrm{t}$ using Algorithm 1.

3: Get values of $\mathrm{C}_{\mathrm{hmg}}, \mathrm{C}_{\mathrm{nmg}}, \mathrm{C}_{\mathrm{g}}$ from step 2,3 and 4 against $\mathrm{PL}_{\mathrm{i}}^{\mathrm{t}}$.

4: Initialize 24 hours time slot of a day, starting from $\mathrm{t}=1$.

5: While $(\mathrm{t}<=24)$ do

If $\left(\mathrm{PL}_{\mathrm{i}}^{\mathrm{t}}>\right)$ then

$\mathrm{PL}_{\mathrm{i}}^{\mathrm{t}}=\mathrm{PL}_{\mathrm{i}}^{\mathrm{t}}-\mathrm{UC}_{\mathrm{hmg}}$

$\mathrm{TC}_{1}=\mathrm{UC}_{\mathrm{hmg}} * \mathrm{C}_{\mathrm{hmg}}$

$\mathrm{UC}_{\mathrm{hmg}}=0$

Else

$\mathrm{UC}_{\mathrm{hmg}}=\mathrm{UC}_{\mathrm{hmg}}-\mathrm{PL}_{\mathrm{i}}^{\mathrm{t}}$

$\mathrm{PL}_{\mathrm{i}}^{\mathrm{t}}=0$

$\mathrm{TC}_{1}=\mathrm{PL}_{\mathrm{i}}^{\mathrm{t}} * \mathrm{C}_{\mathrm{hmg}}$

End If

End While

6: Calculate cost to get remaining $\mathrm{PL}_{\mathrm{i}}^{\mathrm{t}}$ from interested adjacent neighbors with in a cluster.

7: Sort all cost to get $\mathrm{PL}_{\mathrm{i}}^{\mathrm{t}}$ from adjacent neighbors in ascending order.

8: Calculate $\mathrm{TC}_{2}$ to get remaining $\mathrm{PL}_{\mathrm{i}}^{\mathrm{t}}$ from cheapest neighbor.

$\mathrm{PL}_{\mathrm{i}}^{\mathrm{t}}=\mathrm{PL}_{\mathrm{i}}^{\mathrm{t}}-\mathrm{UC}_{\mathrm{nmg}}$

$\mathrm{TC}_{2}=\mathrm{UC}_{\mathrm{nmg}} * \mathrm{C}_{\mathrm{nmg}}$

9: Get remaining $\mathrm{PL}_{\mathrm{i}}^{\mathrm{t}}$ from electricity supplier company (Grid).

$\mathrm{TC}_{3}=\mathrm{PL}_{\mathrm{i}}^{\mathrm{t}} * \mathrm{C}_{\mathrm{g}}$

10: Calculate total cost of single user for time slot t. $\mathrm{TC}=\mathrm{TC}_{1}+\mathrm{TC}_{2}+\mathrm{TC}_{3}$

\section{RESULTS AND DISCUSSION}

This research study was conducted to reduce cost of electricity for end users. The simulation results and performance of OELC mechanism was assessed in this section. The initial data used for simulation was taken from a case study [31]. For simulation, residential area consisting of $\mathrm{N}=4$ smart homes was considered. Every smart home user has around 8 electrical appliances, including some flexible and non-flexible loads. The flexible load includes hair dryer (usage around $2 \mathrm{kWh}$ ), Plug-in hybrid electric vehicles (usage around $9 \mathrm{kWh}$ ), dishwasher (usage around $1.5 \mathrm{kWh}$ ), washing machine (usage around $3.4 \mathrm{kWh}$ ) and entertainment devices like television etc. (usage around $9 \mathrm{kWh}$ ). The non-flexible loads are fridge-freezer (usage around $3 \mathrm{kWh}$ ), lights (usage around $1.7 \mathrm{kWh}$ ) and electric heaters (usage around $6 \mathrm{kWh}$ ). Some assumptions were made to investigate the case study. Firstly, all smart home users' energy requirements are slightly different from each other. Secondly, 24-hour time slots were considered for whole simulation.

Furthermore, cost of electricity is high at start of day and also during evening hours. Moreover, It is assumed that if electricity is demanded from electricity supplier company (grid) then cost function is 0.7 (8 AM-2 PM), 0.4 (2 PM-7 PM), 1 (7 PM-12 AM), 0.3 (12 AM-5 AM), and 0.4 (5 AM-8 AM), respectively as shown in Fig. 2. Simulation test bed is designed using Matlab Simulink.

By implementing the Algorithm 1, the PL Predicted Load) profile of four different smart homes users according to time slot is portrayed in Fig. 3. As explained in Fig. 3, it is assumed that each user electricity demand is slightly different from each other and the demand of electricity is 
high at the beginning hours of the morning (7AM-11AM) and also at beginning hours of the night (7PM- 12AM). According to the proposed OELC mechanism, first the PL of each smart home is fulfilled from in-house mini microgrid. Fig. 4 shows the availability of stored electricity units in 4 different smart homes' mini micro-grids used during simulation. Furthermore, the cost to get PL from each smart home, mini micro-grid $\mathrm{C}_{\mathrm{hmg}}$ is calculated based on Equation (2).
Moreover, according to OELC, each smart home can buy electricity from their adjacent neighbors within a cluster.

Cost to get electricity from adjacent smart home neighbors $\mathrm{C}_{\mathrm{nmg}}$ is stored in matrix form. It is calculated based on Equation (4) and updated at the beginning of every hour. In our case study the matrix shown above is used for simulation. Where rows indicate the buyers

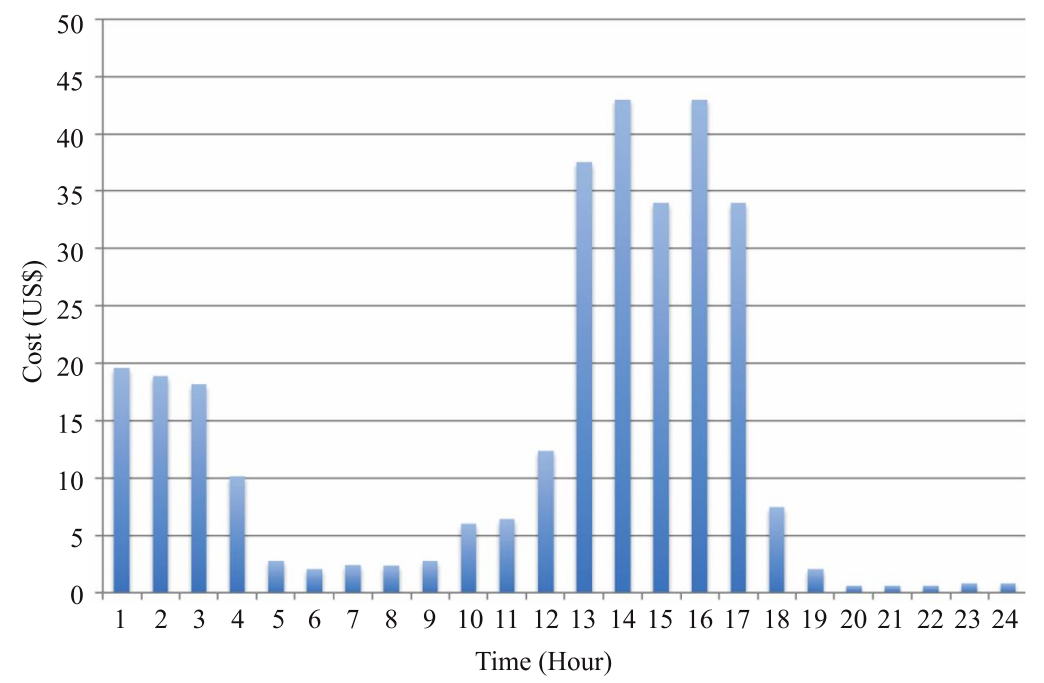

FIG. 2. PER UNIT COST OF ELECTRICITY ACCORDING TO DIFFERENT TIME SLOTS OF A DAY

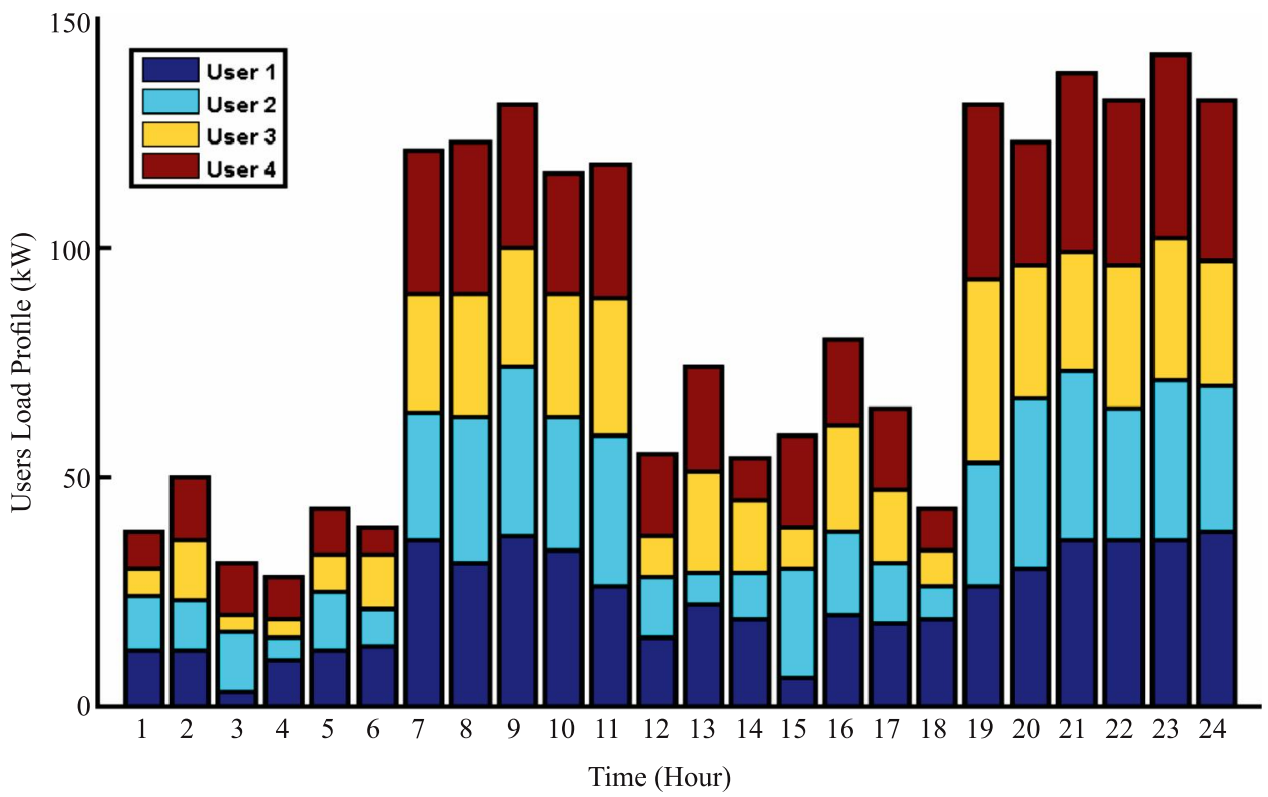

FIG. 3. PREDICTED ELECTRICITY LOAD (PL) PROFILE OF FOUR SMART HOMES USERS ACCORDING TO 24 HOURS TIME SLOTS OF A DAY

Mehran University Research Journal of Engineering \& Technology, Volume 37, No. 4, October, 2018 [p-ISSN: 0254-7821, e-ISSN: 2413-7219] 
smart home and columns indicate the sellers smart homes and the index values represents per unit cost of electricity i.e. the highlighted value in the matrix represent that smart home-3 is ready to sell electricity to smart home-2 at the rate of $4 \$ /$ per unit. A blank space represents that neighboring smart home is not interested to sell electricity.

Furthermore, the cost to get $\left(\mathrm{C}_{\mathrm{g}}\right)$ PL from the grid (electricity supply company) is also calculated using Equation(6). By implementing Algorithm-2, system will calculate the total cost of each smart home user against their PL as shown in Fig. 5. To define a threshold, two different systems are compared. A system without OELC, in which demands of each electrical appliance of every smart home user are assumed to be fulfilled by electricity supply company only (grid station). The second system
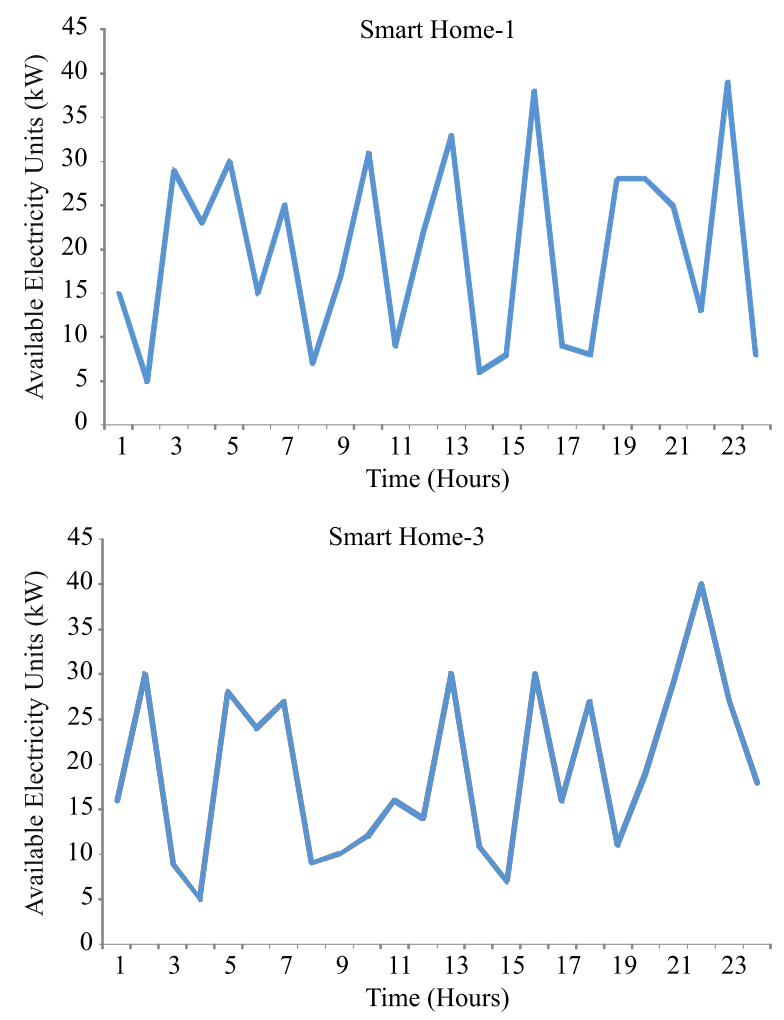

consists of dynamic pricing load shifting, in which flexible loads shift to non-peak hours. The simulation results of electricity cost of each smart home user using OELC system, the system without OELC and dynamic pricing load shifting system are described in Fig. 5. It is clear from the results that there is a significant difference in cost of electricity in three different systems. Cost of electricity for each smart home user is reduced using OELC as well as PAR is also reduced as shown in Table 1. The whole simulation is tested with variable number of parameters including variable size of clusters, different number of smart appliance, variable number of renewable resources but for simplicity we show the results of 4 different smart homes only. Another result about cost of electricity with variable number of smart homes is shown in Fig. 6.
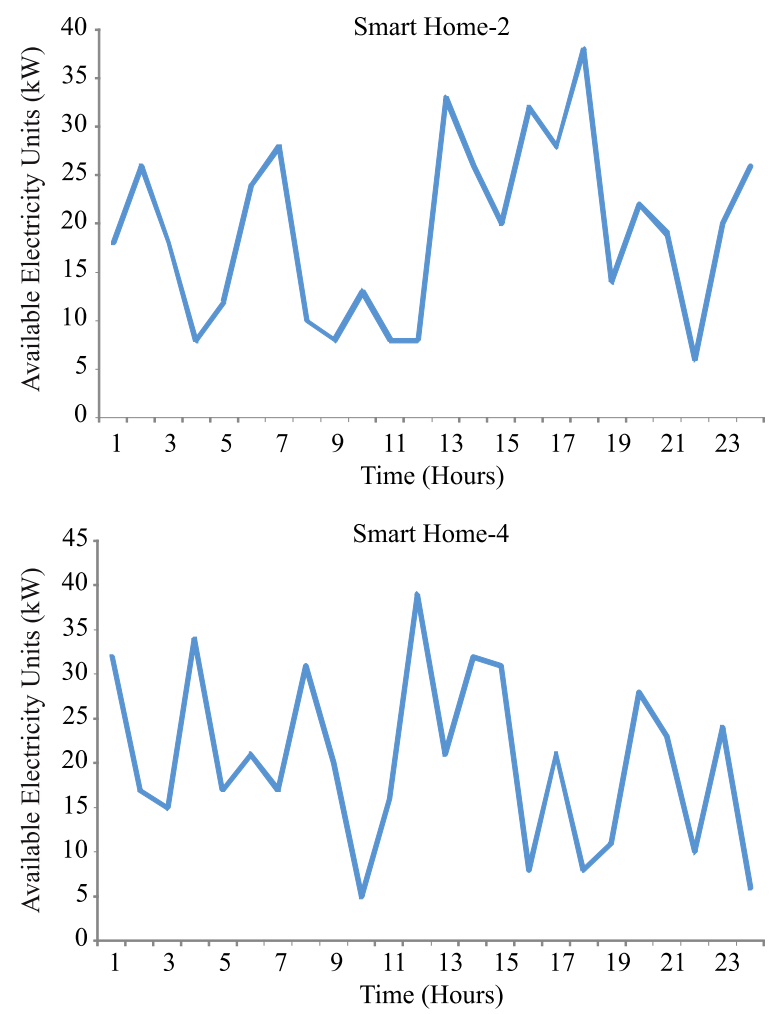

FIG. 4. AVAILABLE UNITS OF ELECTRICITY IN FOUR DIFFERENT SMART HOMES' IN-HOUSE MINI MICRO-GRIDS 

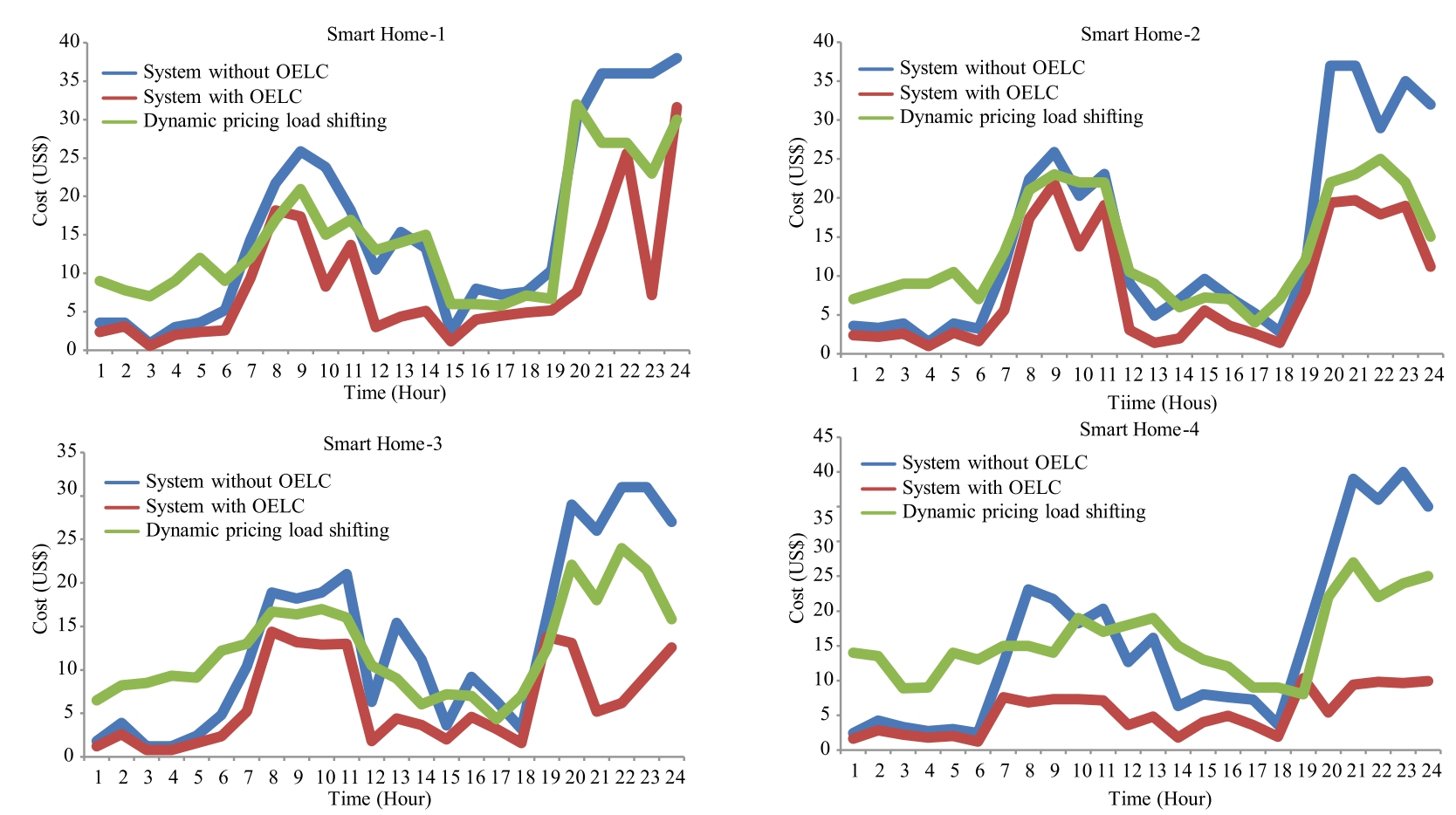

FIG. 5. COMPARISON OF ELECTRICITY COST WITH OELC, WITHOUT OELC AND WITH DYNAMIC PRICING LOAD SHIFTING SYSTEM FOR 4 SAMPLE SMART HOMES USED DURING SIMULATION

TABLE 1. COMPARISON OF ELECTRICITY COST USING OELC, DYNAMIC PRICING LOAD SHIFTING AND SYSTEM WITHOUT OELC

\begin{tabular}{|c|c|c|c|c|}
\hline & Smart Home-1 & Smart Home-2 & Smart Home-3 & Smart Home-4 \\
\hline System without OELC & $\$ 374.7$ & $\$ 348.4$ & $\$ 318$ & $\$ 367.3$ \\
\hline System with OELC & $\$ 200.4$ & $\$ 205.2$ & $\$ 149.3$ & $\$ 126.7$ \\
\hline Dynamic Pricing load shifting & $\$ 348.4$ & $\$ 321$ & $\$ 297.7$ & $\$ 327.4$ \\
\hline
\end{tabular}

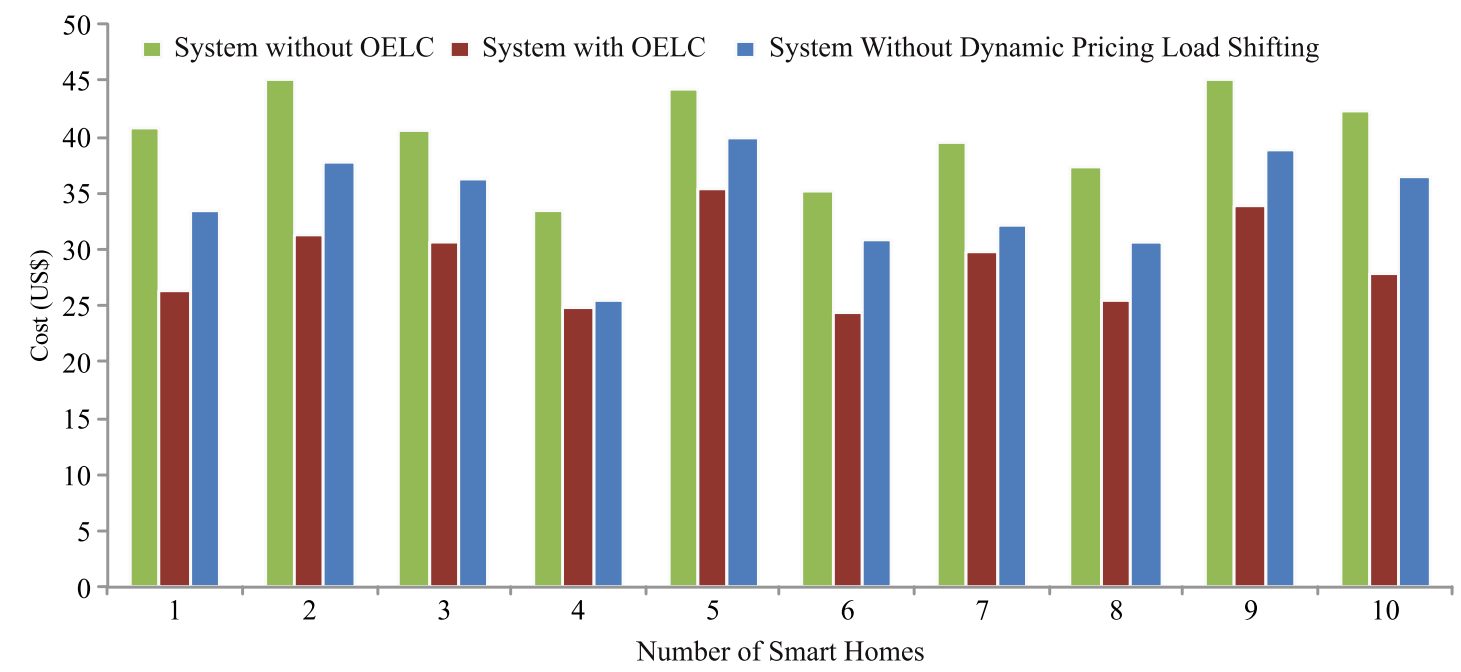

FIG. 6. COMPARISON OF ELECTRICITY COST OF DIFFERENT NUMBER OF SMART HOME USERS USING PROPOSED MECHANISM

Mehran University Research Journal of Engineering \& Technology, Volume 37, No. 4, October, 2018 [p-ISSN: 0254-7821, e-ISSN: 2413-7219] 


\section{CONCLUSION}

In this work, a mechanism OELC is proposed for electricity load and cost optimization. In OELC the demand for electricity is managed during peak hours by considering multiple electricity providers, including inhouse mini micro-grid as well as neighboring smart home's mini micro-grids. To decrease the cost of electricity for end users, bids are collected from multiple resources of electricity against upcoming PL of each consumer. Preference will be given to cheapest resource then move towards higher ones to fulfill the demand. Through simulation analysis, OELC is compared with two other systems; dynamic pricing load shifting and system without OELC. Simulation results confirm that along with the reduction in PAR, electricity consumers achieve a significant difference in their electricity bills using proposed mechanism. The proposed work can be protracted in multiple ways. The benefits of multiple electricity provider companies can be considered and the security issues against malicious users can be studied. In future, more work can be done to secure smart meter and electricity consumption profile of each consumer.

\section{NOMENCLATURE \\ $\mathrm{b}_{\mathrm{m}} \quad$ Buyer micro-grid \\ $\mathrm{C}_{\mathrm{hmg}} \quad$ Cost to get PL from in-house mini micro-grid \\ $\mathrm{C}_{\mathrm{k}} \quad$ Production cost to get electricity from $\mathrm{k}^{\text {th }}$ renewable energy resource. \\ $\mathrm{C}_{\mathrm{nmg}} \quad$ Cost to get PL from neighboring micro-grid. \\ $\mathrm{f}_{\mathrm{j} . \mathrm{t}} \quad$ Advice of $\mathrm{j}^{\text {th }}$ expert agent. \\ $\mathrm{k} \quad$ Number of distributed RE resources. \\ $\mathrm{H}_{\mathrm{hbm}} \quad$ Hourly payback amount of investment.}

Rate at peak and off-peak hour.

Load profile.

$1^{\text {loss }} \quad$ Energy losses during transformation.

$\mathrm{L}_{\mathrm{i}}^{\mathrm{t}} \quad$ Actual load of user $\mathrm{i}$ for time slot $\mathrm{t}$.

$\mathrm{M}_{\mathrm{j}} \quad$ Price of energy, if stored units in RE are received from gird.

PL Predicted load.

$\mathrm{P}_{\mathrm{hmg}} \quad$ Price for bidding.

p Pricing factor.

$\mathrm{p}_{\mathrm{g}} \quad$ Cost to get electricity from grid.

$\mathrm{q}_{\mathrm{g}} \quad$ Quantity of electricity that neighboring microgrid get from grid

$\mathrm{q}_{\text {nmg }} \quad$ Quantity of electricity transferred from neighboring micro-grid.

$\mathrm{q}_{\mathrm{d}} \quad$ Quantity of electricity discharged.

$\mathrm{S}_{\mathrm{c}} \quad$ Storage cost of electricity.

s $\quad$ Storage profile.

$\mathrm{S}_{\mathrm{a}+} \quad$ Charging profile.

$\mathrm{s}_{\mathrm{a}-} \quad$ Discharging profile.

T Threshold; allowable difference between actual and predicted load.

$\mathrm{w}_{(\mathrm{j} ; \mathrm{t}-1)} \quad$ Weight assigned to $\mathrm{j}^{\text {th }}$ expert agents in previous time slot $(\mathrm{t}-1)$.

$\mathrm{x} \quad$ Available units of electricity in RE.

\section{ACKNOWLEDGEMENT}

The authors appreciate the support given by Dr. Wayes Tushar, School of Information Technology \& Electrical Engineering, Faculty of Engineering, Architecture \& Information Technology, Australia. His knowledge of smart grid makes this research worthwhile. 


\section{REFERENCES}

Mishra, A.K., "Energy Optimizations for Smart Buildings and Smart Grids", Ph.D. Dissertation, University of Massachusetts, 2015.

Spiliotis, E., Marinakis, V., Doukas, H., and Psarras, J., "Integrating a Decision Support System with Smart Grid Infrastructures and ICT Solutions Towards Energy Cost Reduction: An Action Plan to Optimally Schedule the Operation of Heating and Electricity Systems", Proceedings of IEEE $7^{\text {th }}$ International Conference on Information, Intelligence, Systems \& Applications, pp. 1-6, 2016.

[3] Joshi, H.I., and Pandya, V.J., "Smart Power Scheduling to Reduce Peak Demand and Cost of Energy in Smart Grid", World Academy of Science, Engineering and Technology, International Journal of Electrical, Computer, Energetic, Electronic and Communication Engineering, Volume 9, pp. 1330-1338, 2016.

[4] El-Hawary, M.E., "The Smart Grid-State-of-the-Art and Future Trends", Electric Power Components and Systems, Volume 42, pp. 239-250, 2014.
Verbong, G.P., Beemsterboer, S., and Sengers, F., "Smart Grids or Smart Users? Involving Users in Developing a Low Carbon Electricity Economy”, Energy Policy, Volume 52, pp. 117-125, 2013.

Fang, X., Misra, S., Xue, G., and Yang, D., "Smart GridThe New and Improved Power Grid: A Survey", IEEE Communications Surveys \& Tutorials, Volume 14, pp. 944-980, 2012.

Mishra, A., Irwin, D., Shenoy, P., Kurose, J., and Zhu, T., "Smartcharge: Cutting the Electricity bill in Smart Homes with Energy Storage", Proceedings of 3rd International Conference on Future Energy Systems: Where Energy, Computing and Communication Meet, pp. 29-37, 2013.

Salinas, S., Li, M., and Li, P., "Multi-Objective Optimal Energy Consumption Scheduling in Smart Grids", IEEE Transactions on Smart Grid, Volume 4, pp. 341-348, 2013.
[9] Amjady, N., Keynia, F., and Zareipour, H., "Short-Term Load Forecast of Microgrids by a New Bilevel Prediction Strategy", IEEE Transactions on Smart Grid, Volume 1, pp. 286-294, 2010.

[10] Logenthiran, T., Srinivasan, D., and Shun, T.Z., "Demand Side Management in Sgrid Using Heuristic Optimization", IEEE Transactions on Smart Grid, Volume 3, pp. 1244-1252, 2012.

[11] Kanchev, H., Lu, D., Colas, F., Lazarov, V., and Francois, B., "Energy Management and Operational Planning of a Microgrid with a PV-Based Active Generator for Smart Grid Applications", IEEE Transactions on Industrial Electronics, Volume 58, pp. 4583-4592, 2011.

[12] Mu, L., Yu, N., Huang, H., Du, H., and Jia, X., “Distributed Real-Time Pricing Scheme for Local Power Supplier in Smart Community", IEEE 22nd International Conference on Distributed Systems, pp. 40-47, 2016.

[13] Liu, Y., Yuen, C., Huang, S., Hassan, N.U., Wang, X., and Xie, S., "Peak-to-Average Ratio Constrained DemandSide Management with Consumer's Preference in Residential Smart Grid”, IEEE Journal of Selected Topics in Signal Processing, Volume 8, pp. 1084-1097, 2014.

[14] Hafeez, G., Javaid, N., Zahoor, S., Fatima, I., and Khan, Z.A., "Energy Efficient Integration of Renewable Energy Sources in Smart Grid", International Conference on Emerging Internetworking, Data \& Web Technologies, pp. 553-562, 2017.

[15] Erol-Kantarci, M., and Mouftah, H.T., "Energy-Efficient Information and Communication Infrastructures in the Smart Grid: A Survey on Interactions and Open Issues", IEEE Communications Surveys \& Tutorials, Volume 17, pp. 179-197, 2015.

[16] Sharma, S., Singh, M., and Prakash, S., "A Novel Energy Management System for Modified Zero Energy Buildings Using Multi-Agent Systems", IEEE Smart Grid and Smart Cities, pp. 267-271, 2017.

[17] Wang, Y., Mao, S., and Nelms, R.M., "Distributed Online Algorithm for Optimal Real-Time Energy Distribution in the Smart Grid", IEEE Internet of Things Journal, Volume 1, pp. 70-80, 2014. 
[18] Molderink, A., Bakker, V., Bosman, M.G., Hurink, J.L., and Smit, G.J., "Management and Control of Domestic Smart Grid Technology", IEEE Transactions on Smart Grid, Volume 2, pp. 109-119, 2010.

[19] Chao, H.P., "Price-Responsive Demand Management for a Smart Grid World", The Electricity Journal, Volume 23, pp. 7-20. 2010.

[20] Zhao, Z., Lee, W.C., Shin, Y., and Song, K.B., “An Optimal Power Scheduling Method for Demand Response in Home Energy Management System", IEEE Transactions on Smart Grid, Volume 43, pp. 1391-1400, 2013

[21] Missaoui, R., Joumaa, H., Ploix, S., and Bacha, S., "Managing Energy Smart Homes According to Energy Prices: Analysis of a Building Energy Management System", Energy and Buildings, Volume 71, pp. $155-167,2014$.

[22] Yaagoubi, N., and Mouftah, H.T., "Energy Trading in the Smart Grid: A Distributed Game-Theoretic Approach", Canadian Journal of Electrical and Computer Engineering, Volume 25, pp. 57-65, 2017.

[23] Joo, I.Y., and Choi, D.H., "Distributed Optimization Framework for Energy Management of Multiple Smart Homes with Distributed Energy Resources", IEEE Access, Volume 5, pp. 15551-15560, 2017.
Zhang, K., Mao, Y., Leng, S., Maharjan, S., Zhang, Y., Vinel, A., and Jonsson, M., "Incentive-Driven Energy Trading in the Smart Grid", IEEE Access, Volume 4, pp. 1243-1257, 2016.

[26] Tushar, W., Chai, B., Yuen, C., Smith, D.B., Wood, K.L., Yang, Z., and Poor, H.V., "Three-Party Energy Management with Distributed Energy Resources in Smart Grid”, IEEE Transactions on Industrial Electronics, Volume 4, pp. 2487-2498, 2015.

Khan, A.R., Mahmood, A., Safdar, A., Khan, Z.A., and Khan, N.A., " Load Forecasting, Dynamic Pricing and DSM in Smart Grid: A Review", Renewable and Sustainable Energy Reviews, Volume 54, pp. 1311-1322, 2016.

[28] Ma, K., Wang, C., Yang, J., Tian, Z., and Guan, X., "Energy Management Based on Demand-Side Pricing: A Supermodular Game Approach", IEEE Access, Volume 5, pp.18219-18228, 2017.

[29] Khan, M. T., Serpanos, D., and Shrobe, H., "ARMET: Behavior-Based Secure and Resilient Industrial Control Systems", Proceedings of the IEEE, 2017.

[30] Afzaal, A., Nazir, M., Ali, A. H., and Sabah, A., "Greennet: Agent Based Energy Load Prediction Techniques for Smart Grid", Bahria University Journal of Information \& Communication Technology, Volume 8, pp. 27-32, 2015 .

[31] Samadi, P., Schober, R., and Wong, V. W., "Optimal Energy Consumption Scheduling Using Mechanism Design for the Future Smart Grid", IEEE International Conference on Smart Grid Communications, pp. 369-374, 2011. 